University of New Hampshire

University of New Hampshire Scholars' Repository

Faculty Publications

$5-11-2011$

\title{
Residence time distributions in surface transient storage zones in streams: Estimation via signal deconvolution
}

\author{
Michael N. Gooseff \\ Pennsylvania State University \\ David A. Benson \\ Colorado School of Mines \\ Martin A. Biggs \\ Colorado School of Mines \\ Mitchell Weaver \\ Pennsylvania State University \\ Wilfred M. Wollheim \\ University of New Hampshire, Durham, wil.wollheim@unh.edu
}

See next page for additional authors

Follow this and additional works at: https://scholars.unh.edu/faculty_pubs

Comments

This is an article published by AGU in Water Resources Research in 2011, available online: https://dx.doi.org/10.1029/

2010WR009959

\section{Recommended Citation}

Gooseff, M., D. A. Benson, M. A. Briggs, M. Weaver, W. M. Wollheim, B. J. Peterson, and C. S. Hopkinson (2011), Residence Time Distributions in Surface Transient Storage Zones in Streams: Estimation Via Signal Deconvolution, Water Resour. Res. 47. W08512, doi:10.1029/2010WR010028

This Article is brought to you for free and open access by University of New Hampshire Scholars' Repository. It has been accepted for inclusion in Faculty Publications by an authorized administrator of University of New Hampshire Scholars' Repository. For more information, please contact Scholarly.Communication@unh.edu. 


\section{Authors}

Michael N. Gooseff, David A. Benson, Martin A. Biggs, Mitchell Weaver, Wilfred M. Wollheim, Bruce J.

Peterson, and Charles S. Hopkinson 


\title{
Residence time distributions in surface transient storage zones in streams : Estimation via signal deconvolution
}

\author{
Michael N. Gooseff, ${ }^{1}$ David A. Benson, ${ }^{2}$ Martin A. Briggs, ${ }^{2}$ Mitchell Weaver, ${ }^{1}$ Wilfred Wollheim, ${ }^{3}$ \\ Bruce Peterson, ${ }^{4}$ and Charles S. Hopkinson ${ }^{5}$ \\ Received 30 August 2010; revised 5 January 2011; accepted 25 January 2011; published 11 May 2011.
}

[1] Little is known about the impact of surface transient storage (STS) zones on reach-scale transport and the fate of dissolved nutrients in streams. Exchange with these locations may influence the rates of nutrient cycling often observed in whole-stream tracer experiments, particularly because they are sites of organic matter collection and lower flow velocities than those observed in the thalweg. We performed a conservative stream tracer experiment (slug of dissolved $\mathrm{NaCl}$ ) in the Ipswich River in northeastern Massachusetts and collected solute tracer data both in the thalweg and adjacent STS zones at three locations in a fifth-order reach. Tracer time series observed in STS zones are an aggregate of residence time distributions (RTDs) of the upstream transport to that point $\left(\mathrm{RTD}_{\mathrm{THAL}}\right)$ and that of the temporary storage within these zones $\left(\mathrm{RTD}_{\mathrm{STS}}\right)$. Here we demonstrate the separation of these two RTDs to determine the RTD $\mathrm{STS}_{\mathrm{ST}}$ specifically. Total residence times for these individual STS zones range from 4.5 to $7.5 \mathrm{~h}$, suggesting that these zones have the potential to host important biogeochemical transformations in stream systems. All of the RTD $\mathrm{STS}_{\mathrm{ST}}$ show substantial deviations from the ideal prescribed by the two-state (mobile/immobile) mass transfer equations. The deviations indicate a model mismatch and that parameter estimation based on the mass transfer equations will yield misleading values.

Citation: Gooseff, M. N., D. A. Benson, M. A. Briggs, M. Weaver, W. Wollheim, B. Peterson, and C. S. Hopkinson (2011), Residence time distributions in surface transient storage zones in streams: Estimation via signal deconvolution, Water Resour. Res., 47, W05509, doi:10.1029/2010WR009959.

\section{Introduction}

[2] Compared to stream advective time scales, stream water (and solute) that is exchanged between the thalweg of a channel and storage zones, such as hyporheic zones and surface transient storage zones (STSs, e.g., side pools, eddies), has downstream transport times that may be substantially increased. This retention of active solutes, particularly in locations where extensive microbial communities and biofilms persist, provides the opportunity for enhanced biogeochemical cycling [e.g., Gooseff et al., 2003; Valett et al., 1996]. Many studies of stream solute transport have attributed transient storage of stream solutes to hyporheic exchange, the movement of stream water through streamadjacent aquifers (the hyporheic zone). Scientists often infer transient storage from late time tailing of solute breakthrough curves observed in the mobile stream and/or spe-

\footnotetext{
${ }^{1}$ Department of Civil and Environmental Engineering, Pennsylvania State University, University Park, Pennsylvania, USA.

${ }^{2}$ Department of Geology and Geological Engineering, Colorado School of Mines, Golden, Colorado, USA.

${ }^{3}$ Institute for the Study of Earth, Oceans, and Space, University of New Hampshire, Durham, New Hampshire, USA.

${ }^{4}$ Ecosystems Center, Marine Biological Laboratory, Woods Hole, Massachusetts, USA. USA.

${ }^{5}$ Department of Marine Sciences, University of Georgia, Athens, Georgia,
}

Copyright 2011 by the American Geophysical Union. 0043-1397/11/2010WR009959 cifically sample the hyporheic zone for introduced conservative and reactive tracers to demonstrate a temporal lag in solute movement through the hyporheic zone [e.g., Harvey et al., 1996]. However, transient storage in STSs may substantially retard solute median travel times in streams, though mean storage residence times are often an order of magnitude shorter in STSs compared to hyporheic storage [Briggs et al., 2010].

[3] Little is understood about the dynamics of mass transfer between the flowing stream thalweg and STS. Because STSs exchange water with thalwegs as a result of the shear stress created between the disparate velocity fields, it is expected that they are more likely to be well mixed than hyporheic zones, which are collections of subsurface interstitial flow paths. In two tundra streams, Gooseff et al. [2008] documented flushing of stream tracer from 12 different STS locations and found that the associated residence time distributions (RTD) demonstrated power law tailing rather than exponential (i.e., characterized by a single rate of mass transfer). However, the study design of Gooseff et al. [2008] precluded the separation of the RTD of solute transport from injection point to STS location in the stream thalweg $\left(\mathrm{RTD}_{\mathrm{THAL}}\right)$, which also demonstrated power law tailing. The significance of STSs to stream chemistry and to life cycles of various biota lies in their potential to be hot spots of biogeochemical cycling, similar to hyporheic zones, in part because of their increased residence time compared to the thalweg of the stream. Ensign and Doyle [2005] created STSs with baffles 
in open channels and noted both enhanced retardation of solute transport and enhanced uptake of ammonium and phosphate compared to the same channels with no baffles in place. In order to improve our understanding of the potential for STS zones to be locations of enhanced biogeochemical cycling, it is important to characterize the residence time dynamics of typical STS zones.

[4] In this investigation we overcome the limitations recognized by Gooseff et al. [2008] by deconvolving RTDs for STSs $\left(\right.$ RTD $\left._{\text {STS }}\right)$ in a fifth-order reach of the Ipswich River, Massachusetts, during a conservative solute release experiment. Stream tracer concentration time series were recorded in each STS and adjacent thalweg. We made use of two numerical methods to deconvolve (i.e., separate) these signals and to determine the $\mathrm{RTD}_{\mathrm{STS}}$ of various zones. Our findings indicate that the exchange between the thalweg and STSs does not follow "ideal" conditions/assumptions (i.e., instantaneous, well mixed, and/or mass preserving) associated with the simple two-state (mobile/immobile) mass transfer concept. Exchange and residence time dynamics are dependent upon the turbulent and momentum exchange dynamics between thalwegs and STSs and the STS internal flow structure. This suggests that RTDs observed in thalwegs are, at least in part, a function of heavy tail exchange processes between STSs and thalwegs.

\section{Methods}

\subsection{Multirate Mass Transfer}

[5] Here we outline our approach for determining RTDs. Let $C_{\mathrm{THAL}}(x, t)$ and $C_{\mathrm{STS}}(x, t)$ denote the thalweg (mobile zone) and STS (i.e., relatively immobile zone) dissolved concentrations. If mass is thought to reversibly transfer between the two zones according to a spectrum of rates (a generalization of the single-rate model), then following Haggerty and Gorelick [1995], Haggerty, McKenna, and Meigs [2000], and Schumer et al. [2003], we may write the multirate mass transfer (MRMT) equations of contaminant transport:

$$
\begin{aligned}
& \frac{\partial C_{\mathrm{THAL}}}{\partial t}+\beta \frac{\partial C_{\mathrm{THAL}}}{\partial t} * g(t)=L_{x} C_{\mathrm{THAL}}-C_{\mathrm{THAL}}(x, t=0) \beta g(t) \\
& \frac{\partial C_{\mathrm{STS}}}{\partial t}+\beta \frac{\partial C_{\mathrm{STS}}}{\partial t} * g(t)=L_{x} C_{\mathrm{STS}}+C_{\mathrm{THAL}}(x, t=0) g(t)
\end{aligned}
$$

where $\beta=V_{\mathrm{STS}} / V_{\mathrm{THAL}}$ is the ratio of water volume in the storage zones and main channel, the asterisk denotes convolution, $g(t)$ is a nonnegative and monotonically decreasing "memory function" that represents the distribution of transfer rates, and $L_{x}$ is a suitable advection-dispersion operator. For classical 1D advection and Fickian dispersion in the thalweg, we may take $L_{x}=-(\partial / \partial x)[v-D(\partial / \partial x)]$, and then $\beta$ is the ratio of the cross-sectional areas $A_{\mathrm{STS}} / A_{\mathrm{THAL}}$. Equation (1) assumes that all solute begins in the mobile, channel zone: $C_{\mathrm{STS}}(x, 0)=0$, although this is easily generalized [Carrera et al., 1998; Schumer et al., 2003]. These initial conditions can also be applied as boundary conditions, effectively eliminating the right-hand parts of the equation (1). Also note that this notation folds the rate of transfer and ratio of areas $\beta$ into a single parameter. For single-rate mass transfer, equation (1) has $g(t)=\omega e^{-\omega t}$, where $\omega=\alpha / \beta$, which is equivalent to $\alpha A_{\text {THAL }} / A_{\text {STS }}$ in the notation used in the OTIS manual (a commonly used transient storage model) [Runkel, 1998].

[6] To show the relationship of the equations for the two phases, we use Fourier and Laplace transforms. As detailed by Benson and Meerschaert [2009], we will denote Fourier transform pairs by $f(x) \leftrightarrow f(k)$, and Laplace transform pairs by $p(t) \leftrightarrow p(s)$. The Fourier transform of the derivative $(d / d x) f(x)$ is $(i k) f(k)$, and the Laplace transform of the derivative $(d / d t) p(t)$ is $s p(s)-p(t=0)$. The advection-dispersion operator has Fourier transform $L_{x} f(x) \rightarrow L(k) f(k)$, and because the transform of a convolution is a product of the transforms, the combined Fourier-Laplace transform (FLT) of the concentration evolution equation (1) leads directly to

$$
\begin{aligned}
& C_{\mathrm{THAL}}(k, s)=\frac{C_{\mathrm{THAL}}(t=0)}{s+s \beta g(s)-L(k)} \\
& C_{\mathrm{STS}}(k, s)=\frac{g(s) C_{\mathrm{THAL}}(t=0)}{s+s \beta g(s)-L(k)} .
\end{aligned}
$$

In this form it is easy to see that the storage zone concentration at any point $x$ is a time convolution of the channel concentration with the function $g(t)$.

[7] Haggerty et al. [2000] and Benson and Meerschaert [2009] discussed the relationship of $g(t)$ with the probability distribution associated with any solute particle remaining in the storage zone for the time period $t$. Specifically, they are related by

$$
g(t)=\lambda P(W>t)
$$

where $1 / \lambda$ is the mean time in the storage zone (when it is defined). This relationship imposes some conditions on the function $g(t)$ that are based on physics. Because $P(W>t)$ is a cumulative distribution function, the function $g(t)$ must be a strictly positive, monotonically decreasing function. Furthermore, because there can be no negative waiting times, $P(W>0)=1$ and $g(0)=\lambda$. Physically, this requires that concentration changes in the thalweg instantaneously influence the storage zone. There is no intermediate state in which solute can "hide" and cause delayed increases in storage zone concentration. If one could measure a realworld memory function that had some deviations from these general constraints on $g(t)$, it would indicate a mismatch between the widely used model in equation (1) and the real system from which data are collected.

\subsection{Field Methods}

[8] We performed a slug addition of $\mathrm{NaCl}(90.4 \mathrm{~kg})$ into a fifth-order reach of the Ipswich River, Massachusetts, in August 2007 (base flow). The channel had a mean depth of $0.6 \mathrm{~m}$ and a mean width of $15.3 \mathrm{~m}$. The solute was mixed with stream water in several large trash cans at approximately $200 \mathrm{~g} \mathrm{NaCl} \mathrm{L}^{-1}$, and the injection was performed by simultaneous pours staggered across the channel at a constricting point formed by a relic beaver dam-a point expected to facilitate rapid mixing across the river cross section. Discharge was measured to be $239 \mathrm{~L} \mathrm{~s}^{-1}$ at the lower reach boundary condition ( $800 \mathrm{~m}$ downstream) based on the dilution of the injected mass. Solute tracer time 
series at $60 \mathrm{~s}$ intervals were recorded in the thalweg adjacent to and within STS zones (from approximately the center of each) using Campbell Scientific data loggers and electrical conductivity/temperature probes attached to rebar at $60 \%$ of depth. $\mathrm{NaCl}$ concentrations were derived from linear relationships with electrical conductivity [Gooseff and McGlynn, 2005; Wondzell, 2006]. STS along the reach was identified through an extensive velocity survey using an electromagnetic velocity meter (Marsh-McBirney model Flomate 2000), and the three zones monitored during the injection were chosen to best represent the dominant reach STS. STS 1 was $185 \mathrm{~m}$ downstream of the injection, a pool on the edge of the channel behind a collection of boulders (approximately $3 \mathrm{~m}$ long, $2 \mathrm{~m}$ wide and $0.25 \mathrm{~m}$ deep). STS 2 was $386 \mathrm{~m}$ downstream of the injection, a side channel with extensive submerged vegetation and woody debris (approximately $12 \mathrm{~m}$ long, $8 \mathrm{~m}$ wide, and $0.5 \mathrm{~m}$ deep). STS 3 was $650 \mathrm{~m}$ downstream of the injection location, a shallow pool on the side of the channel with extensive submerged vegetation (approximately $8 \mathrm{~m}$ long, $3 \mathrm{~m}$ wide, and $0.25 \mathrm{~m}$ deep).

\subsection{Estimating Memory Functions}

[9] We use two methods to estimate $g(t)$ from measured $C_{\text {THAL }}$ and $C_{\text {STS }}$ collected from the same downstream distance $x$ : (1) optimal Wiener filtering [Press et al., 1996] and (2) geostatistical inversion [Cirpka et al., 2007]. Both account for noise that is inherent in the data. The latter also enforces nonnegativity in the filter, which should be considered a desirable trait in the estimator, considering the ideal properties of the filter function $g(t)$. The Wiener filter augments the definition of the deconvolution $g(s)=C_{\mathrm{STS}}(s) /$ $C_{\text {THAL }}(s)$ by recognizing that the measured signal contains both true signal and noise: $C_{\mathrm{STS}}(s)=S(s)+N(s)$. The noise is typically present at much higher frequencies than the signal, so Wiener filtering weights the measured signal according to the fraction of true signal in the measured data: $g(s)=C_{\mathrm{STS}}(s) \Phi(s) / C_{\mathrm{THAL}}(s)$, where $\Phi(s)=|S(s)|^{2} /$ $\left[|S(s)|^{2}+|N(s)|^{2}\right][$ Press et al., 1996]. Properly chosen, the filter weight function $\Phi(s)$ enforces a least squares goodness of fit between the true and estimated $g(t)$ if the signal (concentration) and noise are uncorrelated. In practice, a discrete Fourier transform is used to perform the time deconvolution, and a graph of the power spectra of the data will aid in the estimation of signal versus noise (Figure 1).

[10] The geostatistical inversion assumes that the memory function $g(t)$ "absorbs" the noise of the data and that this noise is autocorrelated. An iterative routine is used to estimate the optimal correlation length in the noise by assuming a linear drop in correlation with time lag. The routine then generates multiple possible realizations of $g(t)$ and minimizes error while enforcing nonnegativity of the function. A range of possible values of $g(t)$ is given, along with the amount of epistemic noise in the data and the range of correlation. More details are given by Cirpka et al. [2007] and Payn et al. [2008]. The latter used this method to estimate retention in streams by deconvolving a downstream breakthrough curve from the upstream input signal. Here we use adjacent main channel and storage zone concentrations, which also overcome the limitations of Gooseff et al. [2008], as they were unable to accurately separate the

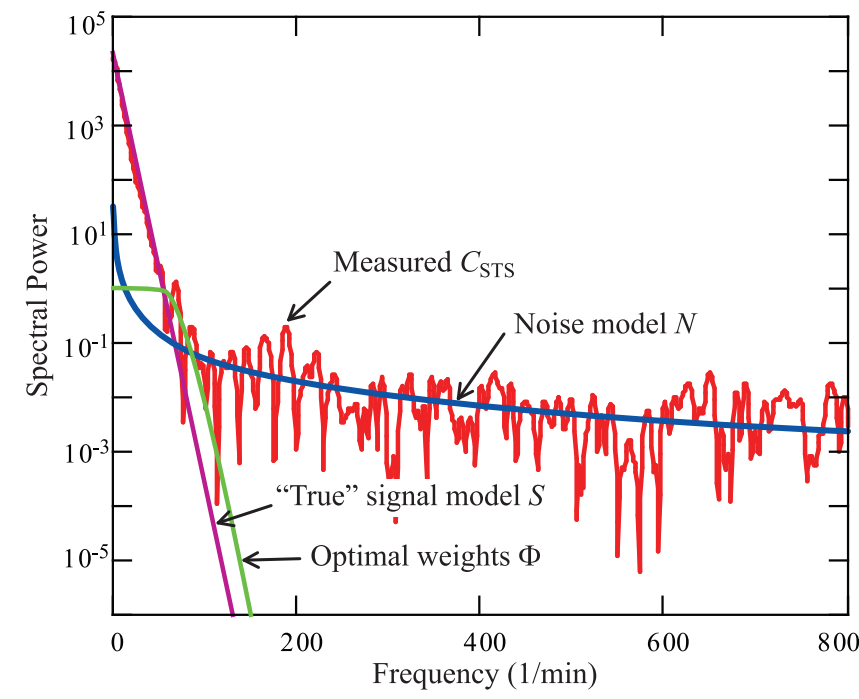

Figure 1. Models for the true signal and noise within the spectrum of measured $C_{\mathrm{STS}}$.

transport residence time distribution from the STS residence time distribution.

\section{Results}

[11] The agreement between Wiener and geostatistical deconvolution ranges from poor (Figure 2e) to good (Figure 2a). Without the enforced nonnegativity, the Wiener filters are able to reconstruct the $C_{\text {STS }}$ breakthrough more closely (e.g., Figure $2 \mathrm{~b}$ inset) but have areas of negative concentration (e.g., Figure $2 \mathrm{~b}$ at 60 and $350 \mathrm{~min}$ ). The main drawback of the Wiener filter is the obvious negative values in estimated $g(t)$. Furthermore, the estimated functions change somewhat on the basis of the chosen noise and true signal models. The geostatistical inversions provide a large number of equiprobable realizations of $g(t)$. Here we show only the means of 100 realizations for each test. The standard deviation of the epistemic error determined in the inversion ranged from 0.4 to $0.8 \mathrm{mg} \mathrm{L}^{-1}$ — about the sensitivity or " $t$ oggling" value of the recording instrument. The slope of the linear variogram for the noise ranged from $6 \times 10^{-7}$ to $3 \times$ $10^{-6} \mathrm{~min}^{-3}$. These low values indicate relatively smooth data [Cirpka et al., 2007].

[12] Estimated $g(t)$ from three tracer tests clearly shows nonideal transfer of mass between the main channel and storage zones (i.e., SRMT and associated assumptions do not adequately describe the RTD). The models commonly used (single-rate mass transfer, or SRMT in OTIS [Runkel, 1998] and MRMT in the work by Haggerty et al. [2002]) assume that there is no delay in fully distributing the mass within a storage zone. Each of the three storage zones in this study show significant delays in the first arrival of mass at the $C_{\mathrm{STS}}$ measurement. This is shown by $g(t)$ that have low values near the origin and peaks some time later. Furthermore, the filter $g(t)$ may show a significant cyclic nature (Figure 2a) that may be caused by slowly rotating water in a large eddy. Peaks occur approximately every $25 \mathrm{~min}$ in STS 1 and every $100 \mathrm{~min}$ in STS 3 (Figures 2a and 2e).

[13] Only one of the storage zone memory functions $g(t)$ shows a general shape dictated by equation (1) (Figure 3 ). 

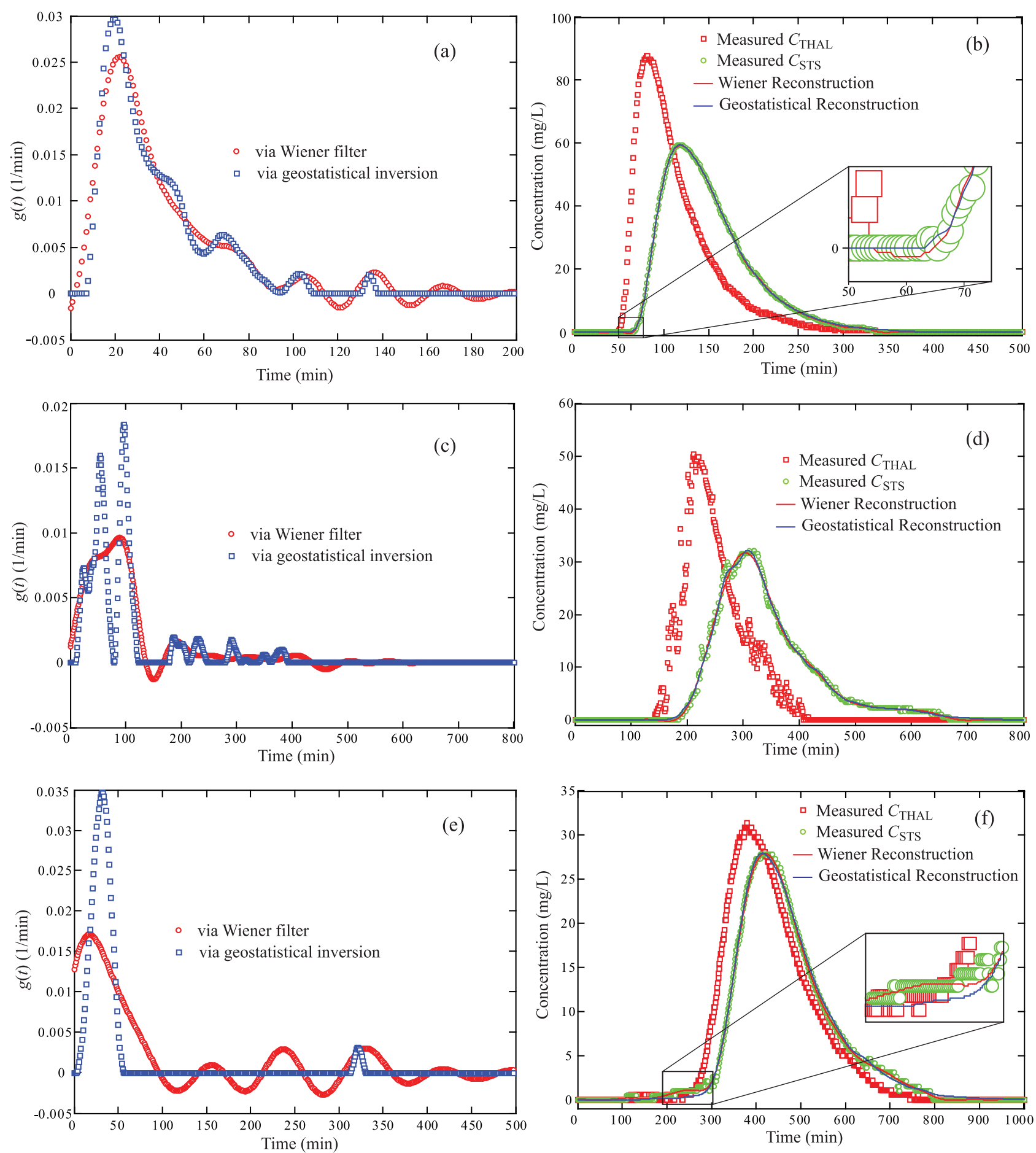

Figure 2. (left) Estimated memory functions $(g(t))$ from the Wiener filter and geostatistical methods. (right) Reconstructed storage zone concentration $\left(C_{\mathrm{STS}}\right)$ histories based on convolving the measured main channel breakthrough curve $\left(C_{\text {THAL }}\right)$ with the estimated filters. Data from STS zones 1,2 , and 3 from top to bottom, respectively.

In this storage zone, the recurring peaks indicate circulation that tends to decay roughly exponentially. For reference, the best fit single-rate (exponential) function $g(t)=$ $0.018 e^{-0.018 t}$, where $t$ is in minutes, was fit to these data (Figure 3) to illustrate the error that a single-rate model will incur, primarily as a result of the late shift in the peak.

\section{Discussion}

[14] Our results indicate that mixing in individual STSs of a natural stream does not follow the expected pattern that would be produced by simple mobile/immobile mass transfer. Therefore, if the $\mathrm{RTD}_{\mathrm{STS}}$ dynamics are to be carefully studied and related to nonconservative solute retention in these specific locations, it is not sufficient to assume 


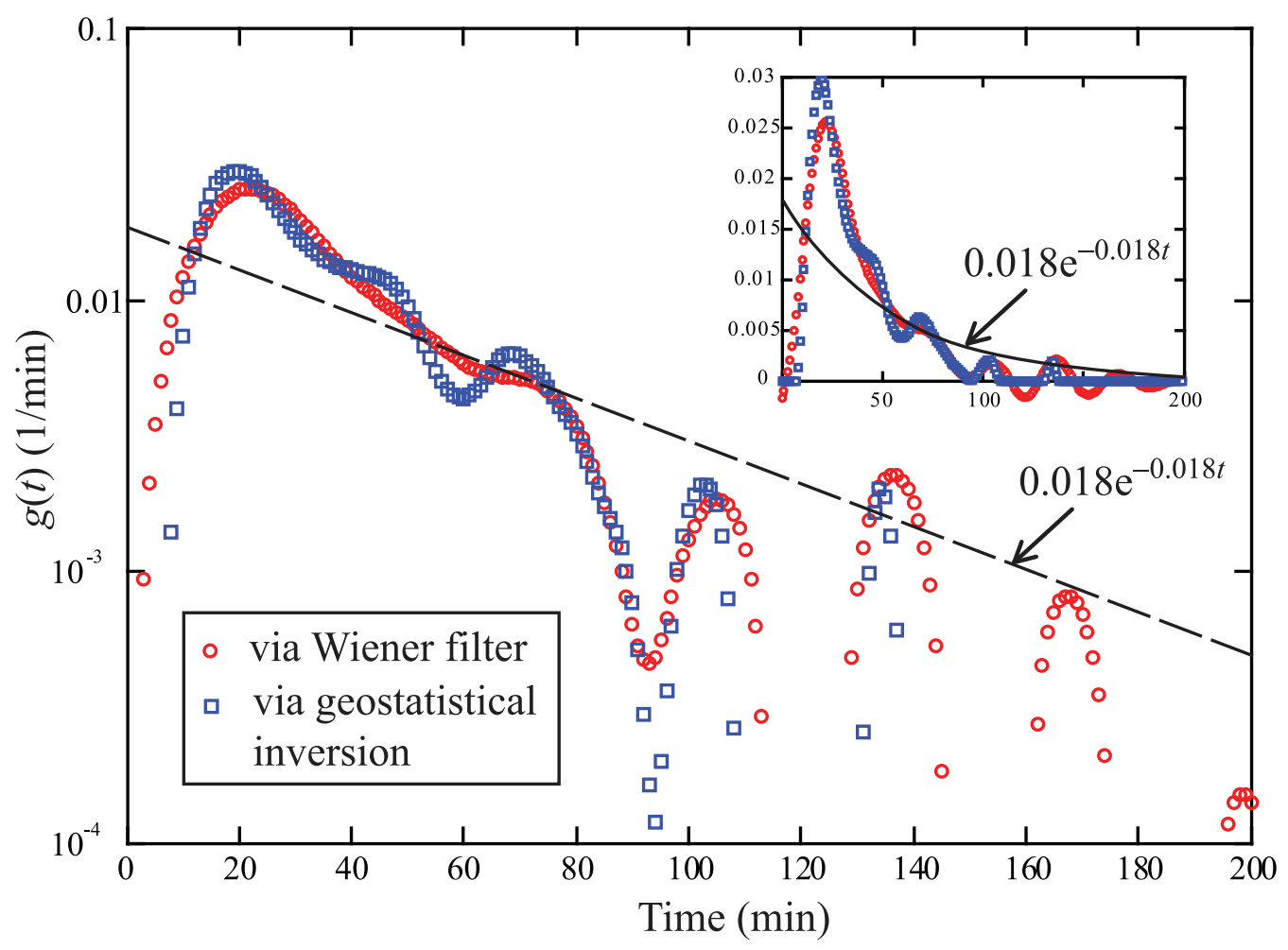

Figure 3. Semilog and linear (inset) plots of estimated filters from STS 1. Peaks show a roughly exponential decay in rough agreement with single-rate mass transfer.

that they are instantaneously well mixed and therefore do not display SRMT or MRMT behavior. This is similar to the finding of transient storage dynamics in hyporheic zones documented by Harvey and Bencala [1993] and Wondzell [2006]. Despite this nonideal mixing caused by MRMT behavior, some tracer $\mathrm{RTD}_{\mathrm{THAL}}$ from wholestream experiments observed in the thalweg and therefore a function of the amalgamated exchange processes that occur along a stream reach have been well characterized by SRMT processes at the reach scale [Gooseff et al., 2008; Payn et al., 2008]. This suggests that the signal observed at the reach scale is not particularly sensitive to the combined influences of many MRMT exchanges occurring at smaller spatial scales. However, there is evidence that thalweg-STS exchange significantly retards solute transport [Briggs et al., 2010] with mean residence times generally on the order of a few hours. These three storage zones have total residence times (i.e., time over which tracer is observed to occur in the STS) of approximately 4.5, 6, and $7.5 \mathrm{~h}$, respectively. It is an open question as to whether this is adequate time to enhance nonconservative solute retention at the scale of the stream reach, which is also a function of reaction rates within STSs.

[15] Whereas Ensign and Doyle [2005] documented enhanced nutrient uptake at the reach scale with artificially introduced STSs, they did not distinguish whether the increased uptake occurred in these lateral zones. It is possible that increased subsurface exchange (i.e., hyporheic exchange and associated transient storage) occurred as a result of the installation of the baffles in their experiment, such that the enhanced uptake occurred in the subsurface rather than the surface locations. Their assessment of hydro- dynamic retention indicates no significant change between the pretreatment and posttreatment results. Hence, retention may very well have been beyond the "window of detection," as defined by sensitivity of the tracer measurement techniques, etc. [Harvey and Wagner, 2000].

[16] Several previous studies have addressed the exchange of water and solutes between rivers and groynes (man-made structures in rivers that serve to add hydraulic roughness and enhanced residence time). Uijttewaal et al. [2001] and van Mazijk [2002] characterized the exchange between thalwegs and STS behind groynes using a first-order mass transfer approach. In particular, Uijttewaal et al. [2001] found that this approach generally fit experimental data from a laboratory model well. Using hydrodynamic approaches, $\mathrm{McC}$ Cy et al. [2008] used two-dimensional large-eddy simulations to characterize exchange between thalwegs and groynes, and Tritthart et al. [2009] have coupled a computational fluid dynamics model with particle tracking to determine residence time dynamics behind groynes. Whereas the hydrodynamics of exchange between thalwegs and STSs behind groynes and between thalwegs and natural STSs are likely similar, the maintenance of groyne fields (i.e., regular dredging and removal of vegetation) and their spacing will influence the internal mixing dynamics of the STSs behind groynes compared to natural STSs. Our STSs are representative of low-gradient coastal rivers, and their internal mixing is made nonideal by the influence of vegetation and irregular lateral cross sections throughout.

[17] The applications of Weiner filtering and geostatistical deconvolution both successfully and similarly characterized the RTD behavior of the STSs in this study. Thus, we have demonstrated that these are appropriate approaches for 
quantifying $\mathrm{RTD}_{\mathrm{STS}} \mathrm{s}$. When coupled with nonconservative solute RTDs, this analysis will be a powerful approach to the determination of the biogeochemical efficacy of STSs, which has, heretofore, not been documented. These locations should be dissimilar from the hyporheic zone because they are generally well lit, likely have temperatures similar to or warmer than that of the thalweg, and may have extensive vegetation and organic matter deposits within them. As a result, they may be very similar to hyporheic zones as "hot spots" of enhanced biogeochemical activity, hosting photochemical reactions, large carbon stores, interactions with biofilms, algae (i.e., heterotrophic and autotrophic communities), and larger vegetation.

[18] All of the measured memory functions $g(t)$ have shapes that do not conform to the ideal shape assumed by the SRMT or MRMT models, commonly assumed in onedimensional solute transport models. There are initial delays and periodicity that we hypothesize to be due to eddy rotation. Additionally, because $g(t)$ in equation (1) is a probability density, it should integrate to unity. The numerically integrated masses of the estimated densities for STS 1, STS 2 , and STS 3 are 0.93(0.94), 0.99(1.0), and 0.95(0.95), respectively, for both methods, where the numbers in parentheses are geostatistically derived. Using the mass transfer model of equation (1) (either singe-rate or multirate) in an optimization routine to estimate parameters will result in concomitant errors in the parameters and possible nonuniqueness of solutions from the model mismatch. Equation (1) assumes a two-state Markov chain between the thalweg and STS states. This model, with suitable $g(t)$, predicts instantaneous rise in the STS breakthrough curve (BTC) with a rise in the thalweg BTC (i.e., the storage zone instantaneously responds to a change in thalweg concentration). In the case of STS 1, an approximately 20 min delay is seen in the real data, which is clearly reflected in the nonideal inverted $g(t)$

\section{Conclusions}

[19] We presented the RTDs of STSs of streams, specifically isolating them from the reach-scale RTDs commonly observed in stream tracer studies. Our results indicate that STSs are not instantaneously or ideally well mixed. We successfully used Weiner filtering and geostatistical inversion to

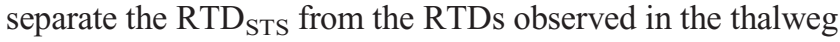
at the same location along the stream reach. RTD dynamics of STSs are important to determining the biogeochemical efficacy of STSs. Given that the role of STSs in nonconservative solute dynamics in streams is under studied, future studies of nonconservative solute dynamics in STSs will benefit greatly from quantification of the RTDs of STSs.

[20] Acknowledgments. The authors would like to acknowledge the helpful reviews of two anonymous reviewers and R. Haggerty, and the logistical support of Kate Morkeski and the Plum Island Ecosystem Long Term Ecological Research project. This research was funded by the National Science Foundation, grants DEB 06-14350 and EAR 0749035, and DOE grant DE-FG02-07ER15841. Findings, opinions, and conclusions do not necessarily represent those of the NSF and DOE.

\section{References}

Benson, D. A., and M. M. Meerschaert (2009), A simple and efficient random walk solution of multi-rate mobile/immobile mass transport equations, Adv. Water Resour., 32(4), 532-539.
Briggs, M. A., M. N. Gooseff, B. J. Peterson, K. Morkeski, W. M. Wollheim, and C. S. Hopkinson (2010), Surface and hyporheic transient storage dynamics throughout a coastal stream network, Water Resour. Res., 46, W06516, doi:10.1029/2009WR008222.

Carrera, J., X. Sánchez-Vila, I. Benet, A. Medina, G. Galarza, and J. Guimerà (1998), On matrix diffusion: Formulations, solution methods and qualitative effects, Hydrogeol. J., 6(1), 178-190.

Cirpka, O. A., M. N. Fienen, M. Hofer, E. Hoehn, A. Tessarini, R. Kipfer, and P. K. Kitanidis (2007), Analyzing bank filtration by deconvoluting time series of electric conductivity, Ground Water, 45(3), 318328.

Ensign, S. H., and M. W. Doyle (2005), In-channel transient storage and associated nutrient retention: Evidence from experimental manipulations, Limnol. Oceanogr., 50(6), 1740-1751.

Gooseff, M. N., and B. L. McGlynn (2005), A stream tracer technique employing ionic tracers and specific conductance data applied to the Maimai catchment, New Zealand, Hydrol. Processes, 19(13), 24912506.

Gooseff, M. N., S. M. Wondzell, R. Haggerty, and J. Anderson (2003), Comparing transient storage modeling and residence time distribution (RTD) analysis in geomorphically varied reaches in the Lookout Creek basin, Oregon, USA, Adv. Water Resour., 26(9), 925-937.

Gooseff, M. N., R. A. Payn, J. P. Zarnetske, W. B. Bowden, J. P. McNamara, and J. H. Bradford (2008), Comparison of in-channel mobile-immobile zone exchange during instantaneous and constant rate stream tracer additions: Implications for design and interpretation of non-conservative tracer experiments, J. Hydrol., 357(1-2), 112-124.

Haggerty, R., and S. M. Gorelick (1995), Multiple-rate mass transfer for modeling diffusion and surface reactions in media with pore-scale heterogeneity, Water Resour. Res., 31(10), 2383-2400, doi:10.1029/ 95WR10583.

Haggerty, R., S. A. McKenna, and L. C. Meigs (2000), On the late-time behavior of tracer test breakthrough curves, Water Resour. Res., 36(12), 3467-3479, doi:10.1029/2000WR900214.

Haggerty, R., S. M. Wondzell, and M. A. Johnson (2002), Power-law residence time distribution in the hyporheic zone of a 2nd-order mountain stream, Geophys. Res. Lett., 29(13), 1640, doi:10.1029/ 2002 GL014743.

Harvey, J. W., and K. E. Bencala (1993), The effect of streambed topography on surface-subsurface water exchange in mountain catchments, Water Resour. Res., 29(1), 89-98, doi:10.1029/92WR01960.

Harvey, J. W., and B. J. Wagner (2000), Quantifying hydrologic interactions between streams and their subsurface hyporheic zones, in Streams and Ground Waters, edited by J. B. Jones and P. J. Mulholland, pp. 3-44, Academic, San Diego, Calif.

Harvey, J. W., B. J. Wagner, and K. E. Bencala (1996), Evaluating the reliability of the stream tracer approach to characterize stream-subsurface water exchange, Water Resour. Res., 32(8), 2441-2451, doi:10.1029/ 96WR01268.

McCoy, A., G. Constantinescu, and L. J. Weber (2008), Numerical investigation of flow hydrodynamics in a channel with a series of groynes, J. Hydraul. Eng., 134(2), 157-172.

Payn, R. A., M. N. Gooseff, D. A. Benson, O. A. Cirpka, J. P. Zarnetske, W. B. Bowden, J. P. McNamara, and J. H. Bradford (2008), Comparison of instantaneous and constant-rate stream tracer experiments through non-parametric analysis of residence time distributions, Water Resour. Res., 44, W06404, doi:10.1029/2007WR006274.

Press, W. H., S. A. Teukolsky, W. T. Vetterling, and B. P. Flannery (1996), Numerical Recipes in FORTRAN 90: The Art of Parallel Scientific Computing, vol. 2, Oxford Univ. Press, Oxford, U.K.

Runkel, R. L. (1998), One-dimensional transport with inflow and storage (OTIS): A solute transport model for streams and rivers, U.S. Geol. Surv. Water Resour. Invest. Rep., 98-4018, 73 pp.

Schumer, R., D. A. Benson, M. M. Meerschaert, and B. Baeumer (2003), Fractal mobile/immobile solute transport, Water Resour. Res., 39(10) 1296, doi:10.1029/2003WR002141.

Tritthart, M., M. Liedermann, and H. Habersack (2009), Modelling spatiotemporal flow characteristics in groyne fields, River Res. Appl., 25(1), 62-81.

Uijttewaal, W. S. J., D. Lehmann, and A. van Mazijk (2001), Exchange processes between a river and its groyne fields: Model experiments, J. Hydraul. Eng., 127(11), 928-936.

Valett, H. M., J. A. Morrice, C. N. Dahm, and M. E. Campana (1996), Parent lithology, surface-groundwater exchange, and nitrate retention in headwater streams, Limnol. Oceanogr., 41(2), 333-345. 
van Mazijk, A. (2002), Modelling the effects of groyne fields on the transport of dissolved matter within the Rhine Alarm-Model, J. Hydrol., 264(1-4), 213-229.

Wondzell, S. M. (2006), Effect of morphology and discharge on hyporheic exchange flows in two small streams in the Cascade Mountains of Oregon, USA, Hydrol. Processes, 20(2), 267-287.

D. A. Benson and M. A. Briggs, Department of Geology and Geological Engineering, Colorado School of Mines, Golden, CO 80401, USA.
M. N. Gooseff and M. Weaver, Department of Civil and Environmental Engineering, Pennsylvania State University, 231P Sackett Bldg., University Park, PA 16802, USA. (mgooseff@engr.psu.edu)

C. S. Hopkinson, Department of Marine Sciences, University of Georgia, Athens, GA 30602, USA.

B. Peterson, Ecosystems Center, Marine Biological Laboratory, Woods Hole, MA 02543, USA.

W. Wollheim, Institute for the Study of Earth, Oceans, and Space, University of New Hampshire, Durham, NH 03824, USA. 